\title{
Linear Pigmented Purpuric Dermatoses
}

\author{
Ayida Al Khalili ${ }^{1}$ and Robin Billick ${ }^{2}$
}
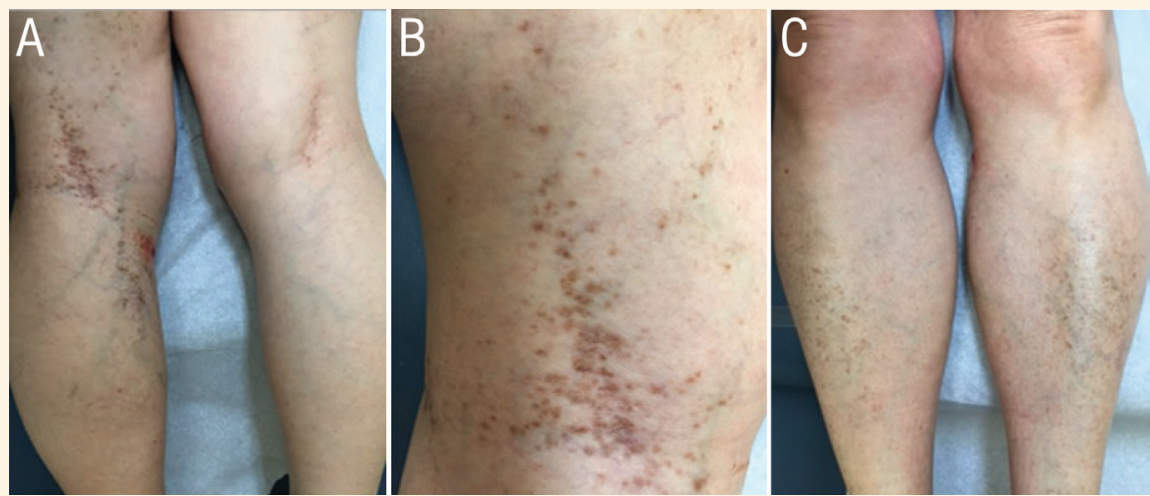

Figure 1: Photograph of (A) brownish non-palpable macules and patches arranged bilaterally in a linear distribution on the back of the legs, with macules on the left leg extending into the posterior thigh. Prominent varicose veins can also be noted, (B) the magnified linear distribution of the eruption affecting the left leg probably following deep venous system and $(\mathbf{C})$ similarly scattered macules distributed across both shins.

\section{A}

65-YEAR-OLD FEMALE PATIENT PRESENTED to a dermatology clinic in Montreal in 2014 with slowly progressing asymptomatic pigmentation in both legs. The condition had lasted for the past few years since the time of presentation. Patient denied any pigmentation elsewhere. There was no history of chronic use of medications or application of medicated creams and the eruption was also not related to sun exposure. The patient had experienced two episodes of lower extremity superficial thrombophlebitis at ages 20 and 50, for which she subsequently underwent varicose vein ligation and stripping of the left lower extremity.

The patient's medical history also included ulcerative colitis on therapy with mesalazine retention enema and surgically treated renal cell carcinoma. A skin examination revealed linear arrangement of brown, muddy, non-palpable and non-blanchable macules and patches located in the popliteal fossa, bilaterally extending to the thighs. Similar macules were seen on both shins scattered with no particular pattern (cayenne pepper appearance) [Figure 1]. Varicose veins and pitting oedema were also noted and peripheral pulses were easily palpated. The differential diagnoses included pigmented purpuric dermatoses (PPD), diabetic dermatopathy, medication-induced pigmentation and purpuric contact dermatitis. The patient's complete blood count and coagulation profile were both normal. Two skin biopsies were obtained and the histopathology revealed superficial perivascular polymorphous dermatitis with erythrocyte extravasation and hemosiderin deposits. This was consistent with Schamberg's purpura and lichenoid lymphocytic infiltrate with grenz zone and hemosiderin deposition more consistent with lichen aureus [Figure 2]. There was no evidence of degeneration in the basal layer of the epidermis. Based on the clinical and histological characteristics, a diagnosis of linear PPD most likely due to venous hypertension was made.

Patient consent was obtained for the publication of these images.

\section{Comment}

PPD are a group of chronic relapsing benign cutaneous entities of unknown aetiology that share similar clinical patterns and histological features. ${ }^{1}$ They generally present as red to purple macules that progressively coalesce and evolve into a golden-brownish colour usually affecting lower extremities. Capillaritis with dilated blood vessels, extravasation of erythrocytes, hemosiderin deposition in papillary dermis and perivascular lymphocytic infiltrate are the histological hallmarks of all PPD. ${ }^{1}$ 


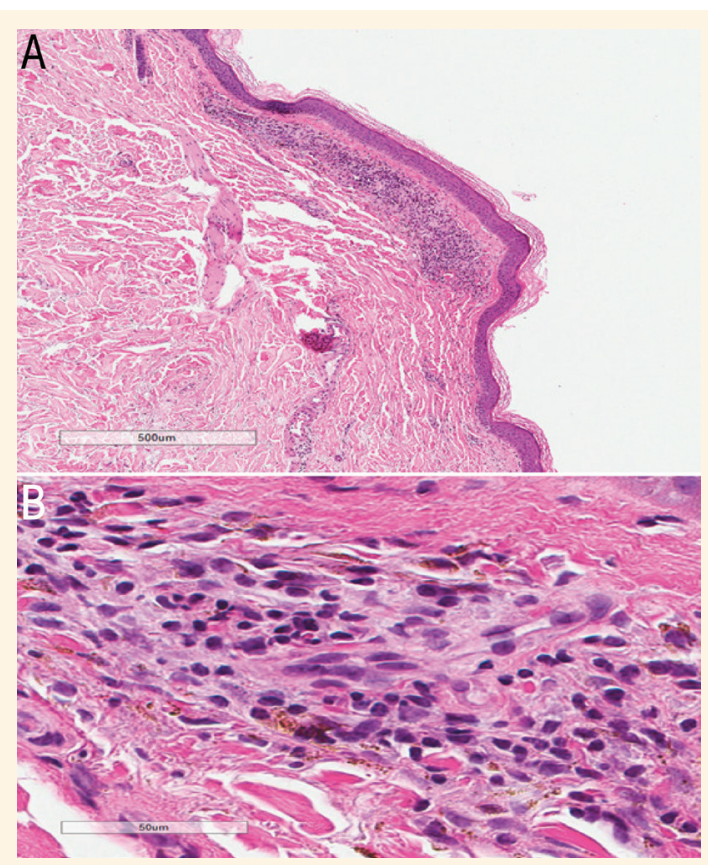

Figure 2: Haematoxylin and eosin stains at $(\mathrm{A}) \times 40$ magnification showing dermal licheniod lymphocytic infiltrate with grenz zone with hemosiderin deposition and no evidence of degeneration in the basal layer of the epidermis and (B) $\times 200$ magnification showing polymorphous perivascular infiltrate with prominent hemosiderin deposition.

There are five major clinical variants: Schamberg's disease (the most common of all presentations), pigmented purpuric lichenoid dermatosis of Gougerot and Blum, purpura annularis telangiectodes of Majocchi, eczematid-like purpura of Doucas and Kapetanakis and lichen aureus. ${ }^{1,2}$ Most PPD are idiopathic, however some are associated with medications or systemic diseases. Moreover, predisposing factors that might influence the disease presentation are venous hypertension, exercise and gravitational dependency, capillary fragility, focal infections and chemical ingestion. ${ }^{1,2}$

Linear PPD have been reported previously as a rare form of PPD, even presenting in a unilateral pattern. ${ }^{3,4}$ The linear array could be blaschkolinear, pseudo-dermatomal or following a deep venous system. ${ }^{3,5}$ In the current case, it was bilaterally distributed and probably following the deep venous system loosely corresponding to the small saphenous vein. Interestingly, the histopathology showed features of both Schamberg's disease and lichen aureus.

Currently, there is no standard therapy for PPD. ${ }^{6}$ In asymptomatic patients, conservative management is preferred. Other topical and oral therapeutic options can also be tried with a variable response. ${ }^{2}$

\section{AUTHORS' CONTRIBUTION}

AAK was involved in data collection, drafting the manuscript, organising article sections, literature review and agreed to be the corresponding author for this article. RB was involved in helping draft the manuscript, interpretation of data, reviewing the content of the article and approving the version of the article to be published. All authors approved the final version of the manuscript.

\section{References}

1. Sardana K, Sarkar R, Sehgal VN. Pigmented purpuric dermatoses: an overview. Int J Dermatol 2004; 43:482-8. https://doi.org/10.1 111/j.1365-4632.2004.02213.x

2. Spigariolo CB, Giacalone S, Nazzaro G. Pigmented Purpuric Dermatoses: A Complete Narrative Review. J Clin Med 2021; 10. https://doi.org/10.3390/jcm10112283.

3. Ruiz-Esmenjaud J, Dahl MV. Segmental lichen aureus: onset associated with trauma and puberty. Arch Dermatol 1988; 124:1572-4. https://doi.org/10.1001/archderm.1988.01670100070024.

4. Taketuchi Y, Chinen T, Ichikawa Y, Ito M. Two cases of unilateral pigmented purpuric dermatosis. J Dermatol 2001; 28:493-8. https://doi.org/10.1111/j.1346-8138.2001.tb00018.x.

5. Hoesly PM, Cappel MA, Sluzevich JC. Persistent dermatomal eruption on a leg. Dermatol Online J 2019; 25:13030/qt2k49w08d. https://doi.org/10.5070/D32510045824.

6. Plachouri KM, Florou V, Georgiou S. Therapeutic strategies for pigmented purpuric dermatoses: A systematic literature review. J Dermatol Treat 2019; 30:105-9. https://doi.org/10.108 0/09546634.2018.1473553. 